\title{
A Novel Analysis Method for Simultaneous Determination of 31 Pesticides by High-Performance Liquid Chromatography-Tandem Mass Spectrometry in Ginseng
}

\author{
Xingang Hou, ${ }^{1}$ Liangyue Liu, ${ }^{1,2}$ Liping Wei, ${ }^{1}$ Da Feng, ${ }^{1,2}$ Meng Lv, ${ }^{1}$ Xiumei Wang, \\ Xiaolong Yu, ${ }^{1}$ Zhongbin $\mathrm{Lu},{ }^{1}$ and Zhiguang Hou $\mathbb{1}^{1}$ \\ ${ }^{1}$ College of Plant Protection, Jilin Agricultural University, Jilin 130118, China \\ ${ }^{2}$ Safety Evaluation Center, Shenyang Research Institute of Chemical Industry, Shenyang 110021, China \\ Correspondence should be addressed to Zhiguang Hou; zhiguanghou@163.com
}

Received 25 July 2021; Revised 24 December 2021; Accepted 29 December 2021; Published 16 February 2022

Academic Editor: Eliseo Herrero Hernandez

Copyright (C) 2022 Xingang Hou et al. This is an open access article distributed under the Creative Commons Attribution License, which permits unrestricted use, distribution, and reproduction in any medium, provided the original work is properly cited.

\begin{abstract}
Ginseng is a perennial herb with a long growth cycle and is known to easily accumulate pesticides during its growth process, seriously threatening people's health. Therefore, to ensure safe consumption, it is necessary to detect and monitor pesticide residues in ginseng. In this study, a novel analysis method was established for simultaneous determination of 31 pesticides in ginseng by high-performance liquid chromatography-mass spectrometry. Ginseng samples were extracted using acetonitrile, cleaned up by primary secondary amine (PSA) solid-phase extraction column eluted with acetonitrile-toluene, and then detected in multiple reaction mode (MRM). The calibration curves of target compounds were linear in the range of $0.005-1.0 \mathrm{mg} / \mathrm{L}$, with correlation coefficients greater than 0.9921 . The limits of detection of all the pesticides in ginseng were between $4.4 \times 10^{-5}$ and $1.6 \times 10^{-2} \mathrm{mg} / \mathrm{kg}$. For fresh ginseng, the average recoveries ranged from 72.1 to $111.6 \%$, and the relative standard deviations were $1.3-12.2 \%$. For dry ginseng, the average recoveries were $74.3-108.3 \%$, and the relative standard deviations were $0.9-14.9 \%$. The residual concentrations of some pesticides in real samples were greater than the maximum residue limit (MRL) for European Union (EU). The method established here is rapid and simple with high sensitivity and good reproducibility, which is sensitive in the residue analysis of many pesticides in ginseng.
\end{abstract}

\section{Introduction}

Ginseng (Panax ginseng C.A. Mey.) is a valuable medicinal plant with a history of more than 2,000 years $[1,2]$. Clinical tests have proven that ginseng plays a role in stimulating blood vessels, regulating nerves, increasing appetite, sedating the brain, restoring fatigue, promoting metabolism, enhancing liver detoxification functions, regulating the endocrine system, improving bone marrow hematopoiesis, and strengthening the body's immune response [3-5]. With the enhancement in health awareness and quality of life, ginseng is widely used in medicine and also has been applied in cosmetics, food, beverage, healthcare, and other industries. The global demand for ginseng exceeds 1,000 tons per year, making outstanding contributions to human health and cultural communication [6-8].
Ginseng is susceptible to diseases and attacks by insects and grass due to its relatively long growth cycle [9-11]. According to statistics, there are more than 40 common diseases and insect pests that can affect the growth of ginseng, and the main diseases include epidemic disease, cataplexy disease, and black spot disease $[12,13]$. There are underground and above-ground pests, and underground pests mainly include pupae, gold needles, maggots, and ground tigers $[14,15]$. Grasshoppers are the main ground pests. They are widely distributed, have a variety of food habits, and are harmful. Ginseng has holes and notches and is vulnerable to disease. Therefore, pest infestation greatly reduces the yield and quality of ginseng (American ginseng). Pesticides play an important role in improving the yield of crops by preventing and treating plant diseases, pests, and weeds [16-19]. Fluconazole, metalaxyl, propiconazole, 
flusilazole, azoxystrobin, and other pesticides are usually used to prevent and treat diseases and pests of ginseng $[16,20]$. However, due to the unreasonable application of pesticides, accumulation of pesticide residues in ginseng has caused concern worldwide.

Accurate and efficient detection methods provide the basis for qualitative and quantitative analysis of pesticides in ginseng. Some studies have reported the detection method of one or a class of pesticides in ginseng [21, 22]. For example, Park et al. established the multiresidue analysis method for fungicides in ginseng [23]. To date, there have been many detection methods for pesticides applied on ginseng which have not been established. The detection methods for azoxystrobin and trifloxystrobin mainly focused on vegetables and fruits, and there was no standard method for residue detection of the above-mentioned pesticides in ginseng [24].

In this study, a solid-phase extraction technique was developed to simultaneously detect 31 pesticides in ginseng by liquid chromatography-tandem mass spectrometry (LCMS), including 11 triazole fungicides, 7 methoxyacrylate fungicides, 1 urethane fungicide, 6 amide fungicides, 1 aniline fungicide, 3 anilinopyrimidine fungicides, 1 neonicotinoid insecticide, and toxic metabolites of fluconazole. This research can provide technical support for the detection of multiple residues of pesticides in ginseng. Moreover, this method can improve analysis efficiency and accuracy and shorten the analysis time.

\section{Materials and Methods}

2.1. Chemicals and Reagents. LC-grade acetonitrile and methanol were purchased from TEDIA (Fairfield, USA). Cleanert $\mathrm{NH}_{2}$-SPE $(500 \mathrm{mg} / 6 \mathrm{ml})$, Cleanert PSA (500 mg/ $6 \mathrm{ml})$, Cleanert PestiCarb SPE $(500 \mathrm{mg} / 6 \mathrm{ml})$, and Cleanert PestiCarb- $\mathrm{NH}_{2}$ SPE $(500 \mathrm{mg} / 6 \mathrm{ml})$ were provided by Agilent. Standards including Thiamethoxam (purity 99.0\%), Triflumizole Metabolite (purity 99.5\%), Cymoxanil (purity 99.5\%), Flumorph (purity 98.0\%), Metalaxyl (purity 99.0\%), Dimethomorph (purity 99.0\%), Pyrimethanil (purity 98.0\%), Epoxiconazole (purity 98.8\%), Flusilazole (purity 98.0\%), Mepanipyrim (purity 99.5\%), Diniconazole (purity 99.0\%), Propiconazole (purity 99.0\%), Dimoxystrobin (purity 99.0\%), Fluoxastrobin (purity 99.3\%), Picoxystrobin (purity 99.0\%), and Pyraclostrobin (purity 99.0\%) were obtained from Dr. Ehrenstorfer $\mathrm{GmbH}$. Myclobutanil (purity 98.6\%), Triadimefon (purity 99.5\%), Tebuconazole (purity 98.8\%), Mandipropamid (purity 99.5\%), Hexaconazole (purity 99.5\%), Cyprodinil (purity 99.5\%), Difenoconazole (purity 99.5\%), Kresoxim-methyl (purity 99.5\%), Procymidone (purity 99.5\%), and Fluazinam (purity 99.5\%) were provided by CHEM CHESTER. Paclobutrazol (purity 99.4\%), Diethofencarb (purity 99.5\%), Azoxystrobin (purity 99.5\%), Trifloxystrobin (purity 98.8\%), and Triflumizole (purity 99.5\%) were purchased from DIKMA. Sodium chloride, anhydrous magnesium sulfate, ammonium acetate, and other analytical-grade reagents were acquired through commercial sources.
2.2. Preparation of Stock Standards. Stock standards $(1000 \mathrm{mg} / \mathrm{L})$ of individual pesticides were prepared using methanol. An appropriate amount of each stock solution was then accurately measured and diluted to mixed standard stock solutions of 100 and $10 \mathrm{mg} / \mathrm{L}$ with methanol. A series of working standards of concentrations of $0.005,0.01,0.02$, $0.05,0.1,0.2,0.5$, and $1.0 \mathrm{mg} / \mathrm{L}$ were prepared by diluting with acetonitrile. The stock standards and working solutions were placed in the dark at $-18^{\circ} \mathrm{C}$ and $4^{\circ} \mathrm{C}$, respectively.

\subsection{Extraction of 31 Pesticides from Ginseng Samples}

2.3.1. Extraction from Fresh Ginseng. Approximately $20 \mathrm{~g}$ of fresh ginseng samples was weighed into a $100 \mathrm{~mL}$ beaker followed by addition of $80 \mathrm{~mL}$ acetonitrile and $10 \mathrm{~mL}$ distilled water and was vortexed for $2 \mathrm{~min}$. The liquid phase was transferred into a $100 \mathrm{~mL}$ cylinder containing $7 \mathrm{~g} \mathrm{NaCl}$, shaken for $10 \mathrm{~min}$, and allowed to stand for $60 \mathrm{~min}$. Subsequently, $10 \mathrm{~mL}$ of acetonitrile was dehydrated into a flask with $5 \mathrm{~g}$ of anhydrous $\mathrm{Na}_{2} \mathrm{SO}_{4}$, followed by evaporating to dryness at $40^{\circ} \mathrm{C}$.

2.3.2. Extraction from Dry Ginseng. Approximately $2.0 \mathrm{~g}$ of powdered ginseng samples was weighed into a $50 \mathrm{~mL}$ Teflon centrifugal tube, $20 \mathrm{~mL}$ acetonitrile and $5 \mathrm{~mL}$ distilled water were added, and the solution was vortexed for $2 \mathrm{~min} .2 .0 \mathrm{~g}$ $\mathrm{NaCl}$ and $4.0 \mathrm{~g}$ anhydrous sodium sulfate were added to each centrifuge tube and vigorously vortexed for $1 \mathrm{~min}$, followed by centrifugation for $5 \mathrm{~min}$ at $5000 \mathrm{rpm} .10 \mathrm{~mL}$ of acetonitrile was dehydrated into a flask with $5 \mathrm{~g}$ of anhydrous $\mathrm{Na}_{2} \mathrm{SO}_{4}$, followed by evaporating to dryness at $40^{\circ} \mathrm{C}$. The residue was dissolved in $2 \mathrm{~mL}$ acetonitrile for cleanup.

2.4. Cleanup of the Extracted Samples. The residue was dissolved in $2 \mathrm{~mL}$ acetonitrile and transferred into a PSA Solid-Phase Extraction (SPE) pretreated with $4 \mathrm{~mL}$ acetonitrile/methyl benzene $(3: 1)$. The column was rinsed with $5 \mathrm{~mL}$ acetonitrile/methylbenzene $(3: 1, \mathrm{v} / \mathrm{v})$. The eluant was collected and evaporated at $40^{\circ} \mathrm{C}$. The extract was dissolved with $2 \mathrm{~mL}$ acetonitrile and filtered through a $0.22 \mu \mathrm{m}$ nylon syringe filter for high-performance liquid chromatography with tandem mass spectrometry (HPLC-MS/MS).

2.5. HPLC-MS/MS Analysis. The 31 pesticides were separated and quantified by liquid chromatography using the Agilent 1260 high performance liquid chromatograph (Agilent, California, USA) in tandem with Agilent $6460 \mathrm{MS} /$ MS systems (Agilent, California, USA) and Agilent Zorbax RRHD Eclipse Plus C18 column $(3.0 \times 100 \mathrm{~mm} 1.8 \mu \mathrm{m})$ (Agilent, California, USA). The optimal baseline separation was obtained with $0.1 \%$ formic acid in a $5 \mathrm{mM}$ ammonium acetate aqueous solution (A) and acetonitrile (B) with a flow rate of $0.4 \mathrm{~mL} / \mathrm{min}$ and an injection volume of $5 \mu \mathrm{L}$ at a column temperature of $30^{\circ} \mathrm{C}$. The gradient program is shown in Table S1.

The analysis was performed in both positive and negative ionization modes. The parameters were as follows: source 
voltages capillary, $3.50 \mathrm{kV}$; atomization and drying gas, 99.95\% nitrogen; collision gas, $99.99 \%$ nitrogen; and desolventizer tube temperature, $400^{\circ} \mathrm{C}$. All parameters for the multiple reaction mode (MRM) transitions, cone voltage, and collision energy were optimized to obtain the highest sensitivity and resolution.

2.6. Method Validation. The linearity, matrix effect, precision, accuracy, limit of detection (LOD), and limit of quantitation (LOQ) were used to evaluate the feasibility of the method for simultaneous determination of 31 pesticides in ginseng. Linearity was assessed by the linear regression of peak areas versus the concentration. The matrix effect should be ignored in the slope ratios of matrix/solvent, ranging from 0.90 to 1.10 [25]. The LOD and LOQ were defined as the concentration that produced a signal-to-noise ratio $(\mathrm{S} / \mathrm{N})$ of 3 and 10, respectively.

Accuracy and precision were evaluated by recoveries and interday and intraday relative standard deviations (RSDs) of five spiked samples replicated at three concentrations over three continuous days. The standard solutions were prepared for each pesticide at $0.01,0.1$, and $1.0 \mathrm{mg} / \mathrm{kg}$; these were used to spike the blank samples of ginseng. The spiked samples were shaken for $1 \mathrm{~min}$ and then left to sit for $2 \mathrm{~h}$. The extraction and cleanup were performed as described above.

2.7. Analysis of Real Samples. The established method was applied to analyze the real samples. The ginseng samples including fresh ginseng and dried ginseng were sampled from market sampling and ginseng planting base in Jilin Province (Ji'an, Baishan, Fusong, and Huanren). All the real samples were extracted and cleanup was performed as described above.

\section{Results and Discussion}

3.1. Optimization of Separation and Detection Conditions. In this study, a series of columns including $\mathrm{C} 8, \mathrm{C} 18, \mathrm{XDB}-$ $\mathrm{CN}$, and $\mathrm{NH}_{2}$ were used to separate the 31 pesticides. Optimal separation was obtained by using Agilent Zorbax RRHD Eclipse Plus C18 $(3.0 \times 100 \mathrm{~mm} 1.8 \mu \mathrm{m})$ column with $0.1 \%$ formic acid in a $5 \mathrm{mM}$ ammonium acetate aqueous solution and acetonitrile as the mobile phase. As shown in Figure 1, all the 31 pesticides were detected within $25 \mathrm{~min}$. Only qualitative and quantitative analysis of Fluazinam was performed in negative ion mode, and the remaining 30 pesticides were detected in the positive ion mode. Precursor ions were selected by the MS Scan mode and the daughter ions were confirmed by the Secondary scan mode. Pesticides were grouped in the order of retention time, the multireaction monitoring scanning methods were edited, and segmented scanning to increase the number of ion scans per unit time and improve detection sensitivity was performed. The optical precursor ions, daughter ions, fragmentor, and collision energy are shown in Table 1.
3.2. Selection of the Extraction Solvent. MeCN, acetone, and EtA care are usually used as the extraction solvents in the multiresidue analysis of a wide range of pesticides with high recoveries [17-20]. Compared with EtAc and acetone, $\mathrm{MeCN}$ is less effective in waxes, fat, and lipophilic pigments [16]. In addition, $\mathrm{MeCN}$ is not compatible with nonpolar solvents (hexane), which can effectively remove lipophilic components [21]. MeCN is compatible with GC applications, and, because of its low viscosity and intermediate polarity, it is very useful in reversed-phase liquid chromatography (LC) and SPE applications. Therefore, MeCN was selected as the extraction solvent in this study. According to previous reports, acidified acetonitrile can improve the recovery of acidic pesticides [22-24]; thus, both acetic acid and hydrochloric acid were used to adjust the $\mathrm{pH}$ of $\mathrm{MeCN}$ from 6 to 2 . However, the recovery results indicated that acidified acetonitrile can improve the recovery of acidic pesticides, and the recovery of basic pesticides (such as imidamide and pyrimidine) is less than $60 \%$.

3.3. Selection of Solid-Phase Extraction Columns. Ginseng has a complex composition and contains a large number of impurities, such as organic acids, volatile oils, and saponins. In order to obtain a good purification, a solid-phase extraction column with better ability to remove polar impurities was selected for purification. Different solid-phase extraction columns including PSA, $\mathrm{NH}_{2}$, Carb, and Carb$\mathrm{NH}_{2}$ column were used to purify the ginseng samples with their respective methods. The results showed that all the good purification results could be obtained with the PSA, Carb- $\mathrm{NH}_{2}$, and Carb column. After purification with $\mathrm{NH}_{2}$ column, the final solution was cloudy. However, the recoveries ranged from $50 \%$ to $70 \%$ after purification with the Carb- $\mathrm{NH}_{2}$ and Carb column. For the PSA column, the recoveries of all 31 pesticides were greater than $75 \%$. Thus, the PSA column was the most suitable choice.

3.4. Method Validation. All the 31 pesticides showed a good linearity in solvent, ranging from 0.005 to $1.0 \mathrm{mg} / \mathrm{kg}$ with an $R^{2}>0.9921$. In this study, when the matrix effect of the pesticide is between 0.9 and 1.1 , the samples are calibrated with the standard curve, and others are calibrated with the matrix standard curve. The LOD and LOQ for 31 pesticides in ginseng were $4.4 \times 10^{-5}-1.6 \times 10^{-2} \mathrm{mg} / \mathrm{kg}$ and $9.0 \times 10^{-5}-3.2 \times 10^{-1} \mathrm{mg} / \mathrm{kg}$, respectively (Table 2). Excellent accuracy and precision of 31 pesticides were obtained in ginseng. Mean recoveries ranged from $72.1 \%$ to $111.6 \%$ with $0.9-14.9 \%$ of intraday $(n=5)$ RSD and $0.6-7.1 \%$ of interday $(n=5) \mathrm{RSD}$. These results indicated that this method could be applied to the simultaneous determination of the 31 pesticides in ginseng (Table 3 ).

3.5. Analysis of Real Samples. The developed simultaneous determination method was applied for determination of 31 pesticides in real samples. In order to ensure the 


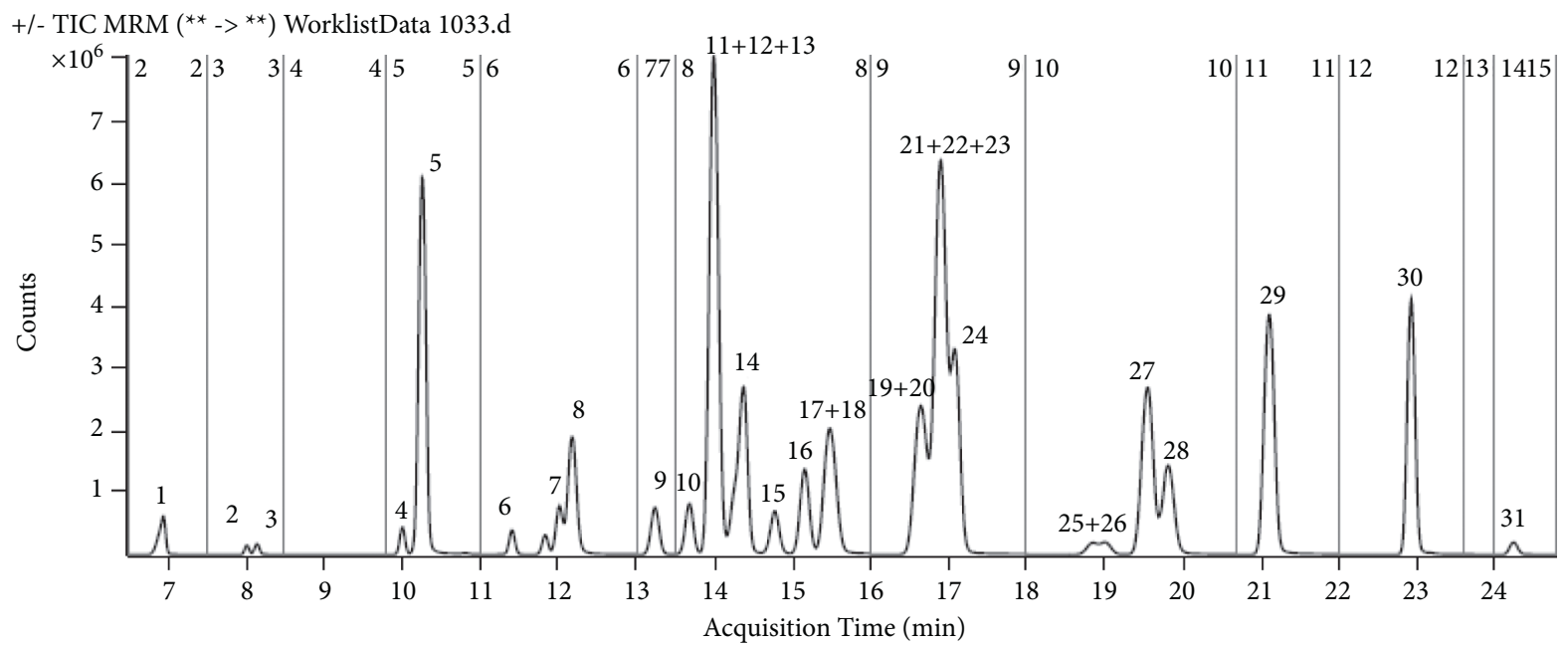

FIGURE 1: High-performance liquid chromatography multiple reaction mode (HPLC-MRM) chromatogram of $1 \mathrm{mg} / \mathrm{L}$ of 31 pesticide standards.

TABLE 1: Mass spectrometry conditions for 31 pesticides.

\begin{tabular}{|c|c|c|c|c|}
\hline Compounds & Precursor ion $(\mathrm{m} / \mathrm{z})$ & Product ion $(\mathrm{m} / \mathrm{z})$ & Fragmentor $(\mathrm{V})$ & Collision energy $(\mathrm{V})$ \\
\hline \multirow{2}{*}{ Thiamethoxam } & \multirow{2}{*}{292} & 181 & 80 & 20 \\
\hline & & 211 & 80 & 10 \\
\hline \multirow{2}{*}{ Triflumizole metabolite } & \multirow{2}{*}{295} & 277.9 & 110 & 3 \\
\hline & & 196 & 110 & 3 \\
\hline \multirow{2}{*}{ Cymoxanil } & \multirow{2}{*}{199.1} & 128.1 & 80 & 15 \\
\hline & & 111.1 & 80 & 20 \\
\hline \multirow{2}{*}{ Flumorph } & \multirow{2}{*}{371.9} & 284.9 & 50 & 14 \\
\hline & & 164.8 & 50 & 26 \\
\hline \multirow{2}{*}{ Metalaxyl } & \multirow{2}{*}{280} & 192 & 120 & 15 \\
\hline & & 220 & 120 & 20 \\
\hline \multirow{2}{*}{ Dimethomorph } & \multirow{2}{*}{388} & 301 & 120 & 20 \\
\hline & & 165 & 120 & 25 \\
\hline \multirow{2}{*}{ Paclobutrazol } & \multirow{2}{*}{294} & 70 & 100 & 15 \\
\hline & & 125 & 100 & 25 \\
\hline \multirow{2}{*}{ Pyrimethanil } & \multirow{2}{*}{200} & 107 & 120 & 25 \\
\hline & & 183 & 120 & 25 \\
\hline \multirow{2}{*}{ Diethofencarb } & \multirow{2}{*}{268} & 152 & 80 & 20 \\
\hline & & 226 & 80 & 5 \\
\hline \multirow{2}{*}{ Myclobutanil } & \multirow{2}{*}{289} & 70 & 120 & 15 \\
\hline & & 125 & 120 & 20 \\
\hline \multirow{2}{*}{ Azoxystrobin } & \multirow{2}{*}{404} & 372 & 120 & 10 \\
\hline & & 344 & 120 & 15 \\
\hline \multirow{2}{*}{ Epoxiconazole } & \multirow{2}{*}{330} & 121 & 120 & 20 \\
\hline & & 141 & 120 & 20 \\
\hline \multirow{2}{*}{ Triadimefon } & \multirow{2}{*}{294} & 69 & 100 & 20 \\
\hline & & 197 & 100 & 15 \\
\hline \multirow{2}{*}{ Mandipropamid } & & 328.2 & 110 & 8 \\
\hline & 412.1 & 125 & 110 & 35 \\
\hline Tebuconazole & & 70 & 100 & 25 \\
\hline Tebuconazole & 308 & 125 & 100 & 25 \\
\hline Flucilazole & 316 & 165 & 120 & 20 \\
\hline Flusilazole & 316 & 247 & 120 & 15 \\
\hline Mepanipyrim & 224 & 106 & 120 & 25 \\
\hline Mepanıpyrım & 224 & 77 & 120 & 30 \\
\hline Hexaconazole & 314 & 70 & 120 & 20 \\
\hline Hexaconazole & 314 & 159 & 120 & 20 \\
\hline & & 70 & 120 & 25 \\
\hline Diniconazole & 326 & 159 & 120 & 30 \\
\hline
\end{tabular}


TABle 1: Continued.

\begin{tabular}{|c|c|c|c|c|}
\hline Compounds & Precursor ion $(\mathrm{m} / \mathrm{z})$ & Product ion $(\mathrm{m} / \mathrm{z})$ & Fragmentor (V) & Collision energy (V) \\
\hline \multirow{2}{*}{ Cyprodinil } & \multirow{2}{*}{226} & 93 & 120 & 40 \\
\hline & & 108 & 120 & 30 \\
\hline \multirow{2}{*}{ Procymidone } & \multirow{2}{*}{284.1} & 256.1 & 140 & 10 \\
\hline & & 145 & 140 & 45 \\
\hline \multirow{2}{*}{ Propiconazole } & \multirow{2}{*}{342.1} & 205 & 130 & 10 \\
\hline & & 159 & 130 & 30 \\
\hline \multirow{2}{*}{ Dimoxystrobin } & \multirow{2}{*}{326.9} & 115.9 & 99 & 22 \\
\hline & & 205 & 99 & 5 \\
\hline \multirow{2}{*}{ Fluoxastrobin } & \multirow{2}{*}{459} & 120 & 110 & 9 \\
\hline & & 137 & 110 & 9 \\
\hline \multirow{2}{*}{ Difenoconazole } & \multirow{2}{*}{406} & 251 & 160 & 20 \\
\hline & & 337 & 160 & 15 \\
\hline \multirow{2}{*}{ Kresoxim-methyl } & \multirow{2}{*}{314} & 131 & 77 & 5 \\
\hline & & 116.1 & 77 & 21 \\
\hline \multirow{2}{*}{ Picoxystrobin } & \multirow{2}{*}{368.17} & 205.13 & 40 & 8 \\
\hline & & 145.12 & 40 & 19 \\
\hline \multirow{2}{*}{ Triflumizole } & \multirow{2}{*}{346} & 73 & 80 & 10 \\
\hline & & 278 & 80 & 5 \\
\hline \multirow{2}{*}{ Pyraclostrobin } & \multirow{2}{*}{388} & 163 & 20 & 10 \\
\hline & & 194 & 20 & 10 \\
\hline \multirow{2}{*}{ Trifloxystrobin } & \multirow{2}{*}{409} & 186 & 120 & 15 \\
\hline & & 206 & 120 & 10 \\
\hline \multirow{2}{*}{ Fluazinam } & \multirow{2}{*}{462.9} & 415.9 & 120 & 20 \\
\hline & & 398 & 120 & 15 \\
\hline
\end{tabular}

Table 2: Retention time, regression equation, correlation coefficient, linear range, and determination limit of 31 pesticides.

\begin{tabular}{|c|c|c|c|c|c|c|}
\hline Compounds & $\begin{array}{l}\text { Retention time } \\
(\min )\end{array}$ & $\begin{array}{c}\text { Regression equation } \\
(\mathrm{X}, \mathrm{mg} / \mathrm{L})\end{array}$ & $\begin{array}{l}\text { Correlation } \\
\text { coefficient }(\mathrm{r})\end{array}$ & $\begin{array}{l}\text { Limit of detection } \\
(\mathrm{mg})\end{array}$ & $\begin{array}{l}\text { Limit of quantitation } \\
(\mathrm{mg})\end{array}$ & $\mathrm{Me}$ \\
\hline Thiamethoxam & 6.947 & $y=3 \mathrm{E}+06 \mathrm{x}+113710$ & 0.9944 & $4.0 \times 10^{-4}$ & $8.3 \times 10^{-4}$ & 0.90 \\
\hline $\begin{array}{l}\text { Triflumizole } \\
\text { metabolite }\end{array}$ & 8.016 & $y=1 \mathrm{E}+06 \mathrm{x}+9183.9$ & 0.9962 & $9.0 \times 10^{-2}$ & $7.0 \times 10^{-3}$ & 0.97 \\
\hline Cymoxanil & 8.144 & $y=2 \mathrm{E}+06 \mathrm{x}+12402$ & 0.9966 & $6.5 \times 10^{-4}$ & $3.2 \times 10^{-4}$ & 0.93 \\
\hline Flumorph & 10.008 & $y=2 E+06 x+1207.1$ & 0.9938 & $4.2 \times 10^{-4}$ & $1.0 \times 10^{-4}$ & 1.00 \\
\hline Metalaxyl & 10.263 & $y=2 \mathrm{E}+07 \mathrm{x}+3019935$ & 0.9994 & $2.4 \times 10^{-4}$ & $8.0 \times 10^{-4}$ & 1.00 \\
\hline Dimethomorph & 11.407 & $y=8 \mathrm{E}+06 \mathrm{x}-21217$ & 0.9921 & $3.6 \times 10^{-3}$ & $8.7 \times 10^{-4}$ & 1.00 \\
\hline Paclobutrazol & 12.022 & $y=7 \mathrm{E}+06 \mathrm{x}+93163$ & 0.9964 & $1.4 \times 10^{-3}$ & $2.4 \times 10^{-3}$ & 1.00 \\
\hline Pyrimethanil & 12.181 & $y=1 \mathrm{E}+07 \mathrm{x}+114381$ & 0.9958 & $2.0 \times 10^{-4}$ & $2.6 \times 10^{-3}$ & 1.00 \\
\hline Diethofencarb & 13.246 & $y=2 E+07 x+428718$ & 0.9944 & $1.0 \times 10^{-3}$ & $8.7 \times 10^{-5}$ & 1.00 \\
\hline Myclobutanil & 13.694 & $y=1 \mathrm{E}+07 \mathrm{x}-22592$ & 0.9947 & $1.2 \times 10^{-3}$ & $3.7 \times 10^{-3}$ & 1.00 \\
\hline Azoxystrobin & 13.994 & $\begin{array}{c}y=7 \mathrm{E}+07 \mathrm{x}+ \\
3322736.6\end{array}$ & 0.9990 & $7.9 \times 10^{-4}$ & $3.3 \times 10^{-4}$ & 1.00 \\
\hline Epoxiconazole & 14.050 & $y=1 \mathrm{E}+07 \mathrm{x}+519680$ & 0.9971 & $8.0 \times 10^{-4}$ & $9.0 \times 10^{-4}$ & 1.00 \\
\hline Triadimefon & 14.264 & $y=7 \mathrm{E}+06 \mathrm{x}+45104$ & 0.9990 & $1.6 \times 10^{-4}$ & $8.0 \times 10^{-5}$ & 0.90 \\
\hline Mandipropamid & 14.377 & $y=2 E+07 x+786506$ & 0.9952 & $1.8 \times 10^{-4}$ & $1.9 \times 10^{-5}$ & 1.00 \\
\hline Tebuconazole & 14.779 & $y=1 \mathrm{E}+07 \mathrm{x}-65825$ & 0.9948 & $1.2 \times 10^{-3}$ & $7.3 \times 10^{-3}$ & 1.00 \\
\hline Flusilazole & 15.161 & $y=5 E+06 x+31258$ & 0.9951 & $1.6 \times 10^{-4}$ & $1.7 \times 10^{-3}$ & 1.00 \\
\hline Mepanipyrim & 15.475 & $y=6 \mathrm{E}+06 \mathrm{x}+406501$ & 0.9972 & $4.4 \times 10^{-5}$ & $3.2 \times 10^{-3}$ & 1.00 \\
\hline Hexaconazole & 15.558 & $y=3 \mathrm{E}+06 \mathrm{x}+17667$ & 0.9957 & $1.1 \times 10^{-3}$ & $1.3 \times 10^{-2}$ & 1.00 \\
\hline Diniconazole & 16.643 & $y=1 \mathrm{E}+07 \mathrm{x}-65825$ & 0.9966 & $5.2 \times 10^{-4}$ & $1.5 \times 10^{-2}$ & 1.00 \\
\hline Cyprodinil & 16.650 & $y=2 \mathrm{E}+07 \mathrm{x}+716715$ & 0.9959 & $4.9 \times 10^{-3}$ & $2.5 \times 10^{-4}$ & 1.00 \\
\hline Procymidone & 16.673 & $y=9 \mathrm{E}+06 \mathrm{x}-3928.2$ & 0.9997 & $5.4 \times 10^{-2}$ & $3.2 \times 10^{-1}$ & 0.96 \\
\hline Propiconazole & 16.775 & $y=1 E+05 x+1071.9$ & 0.9965 & $1.6 \times 10^{-2}$ & $4.7 \times 10^{-3}$ & 0.94 \\
\hline Dimoxystrobin & 16.906 & $y=6 E+06 x+406501$ & 0.9973 & $3.9 \times 10^{-4}$ & $2.7 \times 10^{-3}$ & 1.00 \\
\hline Fluoxastrobin & 17.085 & $y=3 E+07 x+742899$ & 0.9956 & $2.3 \times 10^{-4}$ & $1.3 \times 10^{-4}$ & 0.95 \\
\hline Difenoconazole & 18.851 & $y=2 \mathrm{E}+06 \mathrm{x}-10631$ & 0.9937 & $7.5 \times 10^{-3}$ & $2.7 \times 10^{-3}$ & 0.92 \\
\hline Kresoxim-methyl & 19.037 & $y=2 \mathrm{E}+06 \mathrm{x}+109945$ & 0.9968 & $2.3 \times 10^{-3}$ & $3.3 \times 10^{-4}$ & 1.00 \\
\hline Picoxystrobin & 19.556 & $y=1 E+07 x+879577$ & 0.9960 & $7.6 \times 10^{-5}$ & $9.0 \times 10^{-5}$ & 1.00 \\
\hline Triflumizole & 19.821 & $y=1 \mathrm{E}+07 \mathrm{x}+760728$ & 0.9961 & $1.9 \times 10^{-4}$ & $4.7 \times 10^{-4}$ & 0.94 \\
\hline Pyraclostrobin & 21.107 & $y=2 \mathrm{E}+07 \mathrm{x}+23067.2$ & 0.9981 & $1.2 \times 10^{-4}$ & $5.7 \times 10^{-4}$ & 1.00 \\
\hline Trifloxystrobin & 22.925 & $y=3 \mathrm{E}+07 \mathrm{x}-169245$ & 0.9979 & $5.1 \times 10^{-5}$ & $4.7 \times 10-4$ & 1.00 \\
\hline Fluazinam & 24.243 & $y=7 E+06 x+12129$ & 0.9984 & $2.3 \times 10^{-4}$ & $5.7 \times 10^{-4}$ & 1.03 \\
\hline
\end{tabular}


TABLE 3: Recoveries and precision of detection of 31 pesticides in different ginseng samples $(n=5)$.

\begin{tabular}{|c|c|c|c|c|c|}
\hline Compounds & Spiked level (mg/kg) & Average recovery (\%) (fresh) & RSD (\%) & Average recovery (\%) (dry) & RSD (\%) \\
\hline & 0.01 & 107.3 & 1.3 & 99.7 & 7.7 \\
\hline \multirow{3}{*}{ Thiamethoxam } & 0.1 & 86.8 & 2.2 & 82.3 & 5.7 \\
\hline & 1 & 91.2 & 2.3 & 82.9 & 10.1 \\
\hline & 0.01 & 93.2 & 4.3 & 76.0 & 2.2 \\
\hline \multirow[t]{3}{*}{ Triflumizole metabolite } & 0.1 & 76.7 & 3.5 & 82.8 & 2.7 \\
\hline & 1 & 88.3 & 4.6 & 93.0 & 9.3 \\
\hline & 0.01 & 97.5 & 4.6 & 96.8 & 7.1 \\
\hline \multirow[t]{3}{*}{ Cymoxanil } & 0.1 & 104.2 & 3.8 & 88.0 & 4.7 \\
\hline & 1 & 89.1 & 1.5 & 90.6 & 8.1 \\
\hline & 0.01 & 89.6 & 4.6 & 91.5 & 10.3 \\
\hline \multirow[t]{3}{*}{ Flumorph } & 0.1 & 100.1 & 2.3 & 84.4 & 2.6 \\
\hline & 1 & 89.1 & 1.5 & 90.6 & 8.1 \\
\hline & 0.01 & 111.6 & 3.2 & 104.4 & 4.1 \\
\hline \multirow[t]{3}{*}{ Metalaxyl } & 0.1 & 93.2 & 8.7 & 95.7 & 3.5 \\
\hline & 1 & 93.6 & 2.3 & 90.6 & 10.9 \\
\hline & 0.01 & 79.9 & 4.9 & 91.9 & 8.0 \\
\hline \multirow{3}{*}{ Dimethomorph } & 0.1 & 94.4 & 1.9 & 78.8 & 3.0 \\
\hline & 1 & 84.4 & 2.0 & 86.9 & 11.2 \\
\hline & 0.01 & 100.3 & 3.9 & 85.3 & 9.9 \\
\hline \multirow{3}{*}{ Paclobutrazol } & 0.1 & 80.3 & 4.0 & 86.3 & 1.9 \\
\hline & 1 & 91.7 & 2.2 & 82.6 & 11.5 \\
\hline & 0.01 & 91.7 & 3.6 & 103.3 & 3.2 \\
\hline \multirow[t]{3}{*}{ Pyrimethanil } & 0.1 & 101.9 & 1.8 & 98.4 & 2.5 \\
\hline & 1 & 85.2 & 3.0 & 99.6 & 6.7 \\
\hline & 0.01 & 88.3 & 3.0 & 92.0 & 10.3 \\
\hline \multirow{3}{*}{ Diethofencarb } & 0.1 & 101.9 & 2.7 & 84.4 & 3.8 \\
\hline & 1 & 85.2 & 2.7 & 88.7 & 11.4 \\
\hline & 0.01 & 92.6 & 2.2 & 107.9 & 1.9 \\
\hline \multirow[t]{3}{*}{ Myclobutanil } & 0.1 & 91.6 & 2.3 & 98.6 & 9.9 \\
\hline & 1 & 85.4 & 2.4 & 86.3 & 11.9 \\
\hline & 0.01 & 82.3 & 5.0 & 93.3 & 9.5 \\
\hline \multirow[t]{3}{*}{ Azoxystrobin } & 0.1 & 94.6 & 1.5 & 83.4 & 3.2 \\
\hline & 1 & 87.0 & 2.6 & 89.7 & 13.2 \\
\hline & 0.01 & 88.8 & 4.6 & 92.0 & 11.3 \\
\hline \multirow[t]{3}{*}{ Epoxiconazole } & 0.1 & 103.3 & 1.5 & 86.5 & 2.2 \\
\hline & 1 & 87.2 & 2.3 & 90.9 & 12.5 \\
\hline & 0.01 & 86.3 & 6.3 & 95.1 & 8.0 \\
\hline \multirow[t]{3}{*}{ Triadimefon } & 0.1 & 99.5 & 1.6 & 86.4 & 2.8 \\
\hline & 1 & 87.2 & 2.3 & 90.9 & 12.5 \\
\hline & 0.01 & 89.1 & 4.9 & 108.0 & 2.1 \\
\hline \multirow{3}{*}{ Mandipropamid } & 0.1 & 100.8 & 2.2 & 86.3 & 3.4 \\
\hline & 1 & 86.2 & 2.6 & 86.9 & 14.9 \\
\hline & 0.01 & 83.0 & 3.1 & 92.4 & 10.5 \\
\hline \multirow[t]{3}{*}{ Tebuconazole } & 0.1 & 96.8 & 2.2 & 82.7 & 3.1 \\
\hline & 1 & 85.7 & 1.9 & 86.3 & 11.9 \\
\hline & 0.01 & 91.9 & 3.8 & 88.9 & 12.1 \\
\hline \multirow[t]{3}{*}{ Flusilazole } & 0.1 & 90.9 & 3.7 & 85.6 & 3.2 \\
\hline & 1 & 90.6 & 1.9 & 88.4 & 10.6 \\
\hline & 0.01 & 84.2 & 4.2 & 86.4 & 10.5 \\
\hline Mepanipyrim & 0.1 & 96.7 & 2.0 & 83.4 & 2.7 \\
\hline & 1 & 84.9 & 2.1 & 87.5 & 11.3 \\
\hline & 0.01 & 100.9 & 8.9 & 91.2 & 7.0 \\
\hline Hexaconazole & 0.1 & 95.9 & 2.1 & 81.3 & 4.4 \\
\hline & 1 & 89.6 & 1.8 & 84.1 & 11.6 \\
\hline & 0.01 & 81.5 & 4.4 & 89.1 & 11.5 \\
\hline Diniconazole & 0.1 & 98.6 & 2.0 & 84.1 & 3.3 \\
\hline & 1 & 86.2 & 1.6 & 87.0 & 13.6 \\
\hline & 0.01 & 101.5 & 12.2 & 94.3 & 10.8 \\
\hline Cyprodinil & 0.1 & 92.7 & 8.7 & 95.8 & 2.7 \\
\hline & 1 & 88.9 & 1.9 & 90.5 & 11.7 \\
\hline
\end{tabular}


TABLE 3: Continued.

\begin{tabular}{|c|c|c|c|c|c|}
\hline Compounds & Spiked level (mg/kg) & Average recovery (\%) (fresh) & RSD (\%) & Average recovery (\%) (dry) & RSD (\%) \\
\hline & 0.01 & 101.7 & 3.8 & 105.7 & 2.0 \\
\hline \multirow[t]{3}{*}{ Procymidone } & 0.1 & 105.4 & 2.1 & 92.2 & 4.9 \\
\hline & 1 & 87.3 & 2.8 & 87.3 & 10.3 \\
\hline & 0.01 & 84.3 & 4.5 & 90.5 & 10.9 \\
\hline \multirow[t]{3}{*}{ Propiconazole } & 0.1 & 98.5 & 2.1 & 85.8 & 4.4 \\
\hline & 1 & 88.9 & 1.9 & 90.3 & 10.8 \\
\hline & 0.01 & 86.6 & 4.6 & 91.9 & 9.2 \\
\hline \multirow[t]{3}{*}{ Dimoxystrobin } & 0.1 & 101.1 & 1.4 & 87.6 & 3.8 \\
\hline & 1 & 88.9 & 1.9 & 90.3 & 10.8 \\
\hline & 0.01 & 92.5 & 3.6 & 108.3 & 0.9 \\
\hline \multirow[t]{3}{*}{ Fluoxastrobin } & 0.1 & 90.8 & 3.1 & 89.1 & 3.0 \\
\hline & 1 & 83.0 & 2.1 & 88.2 & 13.8 \\
\hline & 0.01 & 88.8 & 3.2 & 90.3 & 8.5 \\
\hline \multirow[t]{3}{*}{ Difenoconazole } & 0.1 & 90.5 & 3.0 & 87.3 & 3.9 \\
\hline & 1 & 88.1 & 1.9 & 87.3 & 10.6 \\
\hline & 0.01 & 88.9 & 2.8 & 88.5 & 13.7 \\
\hline \multirow[t]{3}{*}{ Kresoxim-methyl } & 0.1 & 93.1 & 1.9 & 84.8 & 2.3 \\
\hline & 1 & 88.5 & 2.0 & 88.8 & 11.6 \\
\hline & 0.01 & 78.7 & 3.1 & 85.3 & 11.8 \\
\hline \multirow[t]{3}{*}{ Picoxystrobin } & 0.1 & 72.1 & 1.6 & 74.3 & 3.4 \\
\hline & 1 & 82.4 & 2.2 & 78.4 & 12.1 \\
\hline & 0.01 & 94.1 & 4.5 & 96.8 & 5.7 \\
\hline \multirow[t]{3}{*}{ Triflumizole } & 0.1 & 100.0 & 2.7 & 85.7 & 3.1 \\
\hline & 1 & 93.5 & 1.9 & 95.6 & 7.7 \\
\hline & 0.01 & 86.2 & 4.3 & 85.1 & 12.0 \\
\hline \multirow[t]{3}{*}{ Pyraclostrobin } & 0.1 & 96.4 & 2.6 & 92.6 & 2.7 \\
\hline & 1 & 104.2 & 3.0 & 97.8 & 4.9 \\
\hline & 0.01 & 87.2 & 3.4 & 91.4 & 10.5 \\
\hline \multirow[t]{3}{*}{ Trifloxystrobin } & 0.1 & 87.2 & 3.7 & 83.9 & 2.8 \\
\hline & 1 & 104.2 & 3.0 & 97.8 & 4.9 \\
\hline & 0.01 & 93.0 & 4.4 & 98.5 & 2.7 \\
\hline \multirow[t]{2}{*}{ Fluazinam } & 0.1 & 91.3 & 2.9 & 81.1 & 2.5 \\
\hline & 1 & 89.7 & 2.8 & 94.9 & 2.1 \\
\hline
\end{tabular}

authenticity of the test results during the analysis process, the specificity of the analytical method was confirmed by injecting the quality control samples with each batch of the real samples. All the determination results are shown in Tables S2 to S6. Apart from procymidone, no other pesticides were detected in dried ginseng and fresh ginseng. However, the residual concentrations of procymidone in dried and fresh ginseng were below the MRL value from EU. Procymidone, Tebuconazole, Azoxystrobin, Mandipropamid, and Cyprodinil were detected on the fresh ginseng from the planting base. Twelve pesticides, Procymidone, Propiconazole, Tebuconazole, Difenoconazole, Azoxystrobin, Pyraclostrobin, Diethofencarb, Mandipropamid, Cyprodinil, Pyrimethanil, Thiamethoxam, and Dimethomorph, were detected on the dried ginseng from the planting base. The residual concentrations of these pesticides were below the MRL from EU except Procymidone, Tebuconazole, Mandipropamid, and Cyprodinil. These measurement data show that there is pesticide residue pollution in the ginseng in China's current market, which has also led to the frequent return of China's exported ginseng. Therefore, the relevant testing departments should increase the testing of ginseng, strictly check the unqualified ginseng, prohibit its circulation in the market, and ensure China's international reputation to improve import and export trade.

\section{Conclusions}

In this study, a novel analysis method was established for the simultaneous determination of 31 pesticides in ginseng by HPLC-MS/MS. Compared with other methods, this method can simultaneously detect 31 pesticides in fresh ginseng and dried ginseng, with good resolution and sensitivity. The advantages of this method include simple pretreatment, short sample processing time, fast detection speed, and effective elimination of complex matrix interferences of ginseng samples. At the $0.01,0.1$, and $1.0 \mathrm{mg} / \mathrm{kg}$ spiked concentrations, the main average recoveries ranged from 72.1 to $111.6 \%$, with RSD values of $1.3-12.2 \%$ in fresh ginseng and from 74.3 to $108.3 \%$, with RSD values of $0.9-14.9 \%$ in dry ginseng. The recovery and accuracy of the method meet the requirements of pesticide residue analysis, and it is suitable for the simultaneous detection of multiple pesticides in ginseng. The data from the analysis of real samples indicated that there is pesticide residue pollution in the ginseng in 
China's current market. Although reasonable application of pesticides is essential, this situation must be carefully monitored.

\section{Data Availability}

Processed data used to support the findings of this study are included within the article. Some of the data related to the validation of the developed method are also included within the article, while others are included as Supplementary Materials (S1-S6).

\section{Conflicts of Interest}

The authors declare that there are no conflicts of interest.

\section{Acknowledgments}

This work was financially supported by the Agricultural Industry Standard of Ministry of Agriculture and Rural Affairs (2018) (181721301092371097) and the Special Fund for Ginseng Industry Development of Jilin Province (2015) (201501). The funding agency is sincerely acknowledged by the authors.

\section{Supplementary Materials}

Table S1: the gradient program for simultaneous determination of 31 pesticides. Table S2: pesticide residues in dried ginseng and fresh ginseng from market $(\mathrm{mg} / \mathrm{kg})$. Table S3: pesticide residues in fresh ginseng from planting base $(\mathrm{mg} / \mathrm{kg})$. Table S4: pesticide residues in fresh ginseng from planting base $(\mathrm{mg} / \mathrm{kg})$. Table S5 and Table S6: pesticide residues in dried ginseng from planting base $(\mathrm{mg} / \mathrm{kg})$. (Supplementary Materials)

\section{References}

[1] H.-F. Lu, Y.-H. Lai, H.-C. Huang et al., "Ginseng-plus-Bai$\mathrm{Hu}$-Tang ameliorates diet-induced obesity, hepatic steatosis, and insulin resistance in mice," Journal of Ginseng Research, vol. 44, no. 2, pp. 238-246, 2020.

[2] M. E.-A. Farh, Y.-J. Kim, R. Abbai et al., "Pathogenesis strategies and regulation of ginsenosides by two species of Ilyonectria in Panax ginseng: power of speciation," Journal of Ginseng Research, vol. 44, no. 2, pp. 332-340, 2020.

[3] C.-J. Yao, J.-M. Chow, S.-E. Chuang et al., "Induction of Forkhead Class box O3a and apoptosis by a standardized ginsenoside formulation, KG-135, is potentiated by autophagy blockade in A549 human lung cancer cells," Journal of Ginseng Research, vol. 41, no. 3, pp. 247-256, 2017.

[4] J. Kim, H. Lee, K. S. Kang, K.-H. Chun, and G. S. Hwang, "Protective effect of Korean Red Ginseng against glucocorticoid-induced osteoporosis in vitro and in vivo," Journal of Ginseng Research, vol. 39, no. 1, pp. 46-53, 2015.

[5] H. J Kim, S. W Jung, S. Y Kim et al., "Panax ginseng as an adjuvant treatment for Alzheimer's disease," Journal of ginseng research, vol. 42, no. 2, pp. 401-411, 2018.

[6] Z. A. Ratan, M. F. Haidere, Y. H. Hong et al., "Pharmacological potential of ginseng and its major component ginsenosides," Journal of Ginseng Research, vol. 45, no. 2, pp. 199-210, 2021.
[7] Kim, "Beneficial effects on skin health using polysaccharides from red ginseng by-product," Journal of Food Science, vol. 43, no. 8, Article ID e12961, 2019.

[8] S.-W. Song, H.-N. Kim, J.-Y. Shim et al., "Safety and tolerability of Korean Red Ginseng in healthy adults: a multicenter, double-blind, randomized, placebo-controlled trial," Journal of Ginseng Research, vol. 42, no. 4, pp. 571-576, 2018.

[9] Soo, "Development of a biofungicide using a mycoparasitic fungus simplicilliumlamellicola BCP and its control efficacy against gray mold diseases of tomato and ginseng," Journal of Plant Pathology, vol. 33, no. 3, pp. 337-344, 2017.

[10] M. Song, H. Y. Yun, and Y. H. Kim, "Antagonistic Bacillus species as a biological control of ginseng root rot caused by Fusarium cf. incarnatum," Journal of Ginseng Research, vol. 38, no. 2, pp. 136-145, 2014.

[11] Y. C. Kim, J. H. Lee, Y.-S. Bae, B.-K. Sohn, and S. K. Park, "Development of effective environmentally-friendly approaches to control Alternaria blight and anthracnose diseases of Korean ginseng," European Journal of Plant Pathology, vol. 127, no. 4, pp. 443-450, 2010.

[12] Z. K. Punja, A. Wan, and R. S. Goswami, "Root rot and distortion of ginseng seedling roots caused byFusarium oxysporum," Canadian Journal of Plant Pathology, vol. 30, no. 4, pp. 565-574, 2008.

[13] Z. K. Punja, A. Wan, L. Leippi, R. S. Goswami, and J. Jayaraj, "Growth, pathogenicity and infection behaviour, and genetic diversity ofRhexocercosporidium panicisisolates from ginseng roots in British Columbia," Canadian Journal of Plant Pathology, vol. 35, no. 4, pp. 503-513, 2013.

[14] S. N. Hill and M. K. Hausbeck, "Evaluation of TOM-CAST in timing fungicide sprays for management of alternaria blight on American ginseng," Plant Disease, vol. 92, no. 12, pp. 1611-1615, 2008.

[15] Xi, "De novo transcriptome analysis of gene responses to pest feeding in leaves of Panax ginseng C," Molecular Medicine Reports, vol. 20, no. 1, pp. 433-444, 2019.

[16] S. Liang, X. Xu, and Z. Lu, "Effect of azoxystrobin fungicide on the physiological and biochemical indices and ginsenoside contents of ginseng leaves," Journal of Ginseng Research, vol. 42, no. 2, pp. 175-182, 2018.

[17] L. V. Podhorniak, "A rapid miniaturized residue analytical method for the determination of zoxamide and its two acid metabolites in ginseng roots using UPLC-MS/MS," Journal of Agricultural and Food Chemistry, vol. 62, no. 17, pp. 37023709, 2014.

[18] K.-G. Lee and E.-K. Jo, "Multiresidue pesticide analysis in Korean ginseng by gas chromatography-triple quadrupole tandem mass spectrometry," Food Chemistry, vol. 134, no. 4, pp. 2497-2503, 2012.

[19] X. Qi, "Development of a matrix solid-phase dispersionsonication extraction method for the determination of fungicides residues in ginseng extract," Food Chemistry, vol. 121, no. 3, pp. 758-762, 2010.

[20] Keyal, "Drug interaction of traditional Chinese medicines with fluconazole against fluconazole resistant strains of Candida albicans," International Journal of Clinical and Experimental Medicine, vol. 9, no. 11, pp. 22357-22362, 2016.

[21] X. Liu, L. Wang, H. Li, J. Yin, S. Lv, and K. Zhu, "Investigation of the presence of 22 organochlorine pesticide residues in ginseng from Jilin Province, China," Journal of Food Protection, vol. 82, no. 9, pp. 1625-1629, 2019.

[22] T.-R. Kim, K.-H. Park, M.-R. Jang et al., "Evaluation of residual pesticides in fresh ginseng collected in seoul," Journal of Applied Biological Chemistry, vol. 56, no. 1, pp. 29-35, 2013. 
[23] Y.-S. Park, A. M. Abd El-Aty, J.-H. Choi, S.-K. Cho, D.-H. Shin, and J.-H. Shim, "Pesticide multiresidue analysis inPanax ginseng (C. A. Meyer) by solid-phase extraction and gas chromatography with electron capture and nitrogenphosphorus detection," Biomedical Chromatography, vol. 21, no. 1, pp. 29-39, 2007.

[24] I. Giza and U. Sztwiertnia, "Gas chromatographic determination of azoxystrobin and tifloxystrobin residues in apple," Acta Chromatographica, vol. 13, pp. 226-228, 2003.

[25] F. Xu, W. Ren, X. Fang, L. Chen, and X. Zha, "Residues, dissipation, and safety evaluation of pymetrozine-clothianidin mixture in strawberry," Environmental Science and Pollution Research, vol. 28, no. 18, pp. 22641-22650, 2021. 